\title{
Effect of different stress conditions on the stability of quercetin-loaded lipid microparticles produced with babacu (Orbignya speciosa) oil: evaluation of their potential use in food applications
}

\author{
Camila Pinheiro Silva CAZADO ${ }^{1}$, Samantha Cristina de $\mathrm{PINHO}^{1 \star}$
}

\begin{abstract}
Lipid micro and nanoparticles have been extensively investigated as carriers for hydrophobic bioactives in food systems because they can simultaneously increase the dispersibility of these lipophilic substances and help improve their bioavailability. In this study, lipid microparticles of babacu oil and denatured whey protein isolate were produced, and their ability to protect quercetin against degradation was evaluated over 30 days of storage. Additionally, the lipid microparticles were subjected to the typical stress conditions of food processing (presence of sucrose, salt, and thermal stresses), and their physico-chemical stability was monitored. The data show that the babacu microparticles efficiently avoided the oxidation of quercetin because $85 \%$ of the initial amount of the flavonoid was preserved after 30 days. The particles were notably stable up to a temperature of $70{ }^{\circ} \mathrm{C}$ for 10 minutes at relatively high concentrations of salt and sucrose. The type of stirring (mechanical or magnetic) also strongly affected the stability of the dispersions.
\end{abstract}

Keywords: lipid microparticles; Orbignya speciosa; quercetin; stress conditions.

Practical Application: Microencapsulation of quercetin for incorporation in food.

\section{Introduction}

Several hydrophobic bioactives are notably interesting in food applications, but they have limited incorporation because of the difficulty of their dispersion in aqueous media. Several lipid-based microencapsulation systems are available to encapsulate, protect and deliver such hydrophobic bioactive compounds in the form of lipid droplets (emulsions, nanoemulsions, multiple emulsions), liposomes and solid lipid particles (McClements, 2010; McClements \& Li, 2010). Solid lipid particles (micro or nano) are encapsulation systems that are similar to the conventional oil-in-water $(\mathrm{o} / \mathrm{w})$ emulsions, but their lipid core is composed of a solid lipid (solid at room temperature) (Müller et al., 2000; Mehnert \& Mäder, 2001). The advantages of using these particles to encapsulate hydrophobic bioactives include their full biodegradability, full biocompatibility and high capacity for incorporating lipophilic molecules (Müller et al., 2000). In-addition, lipid-based matrices improve the bioavailability of lipophilic bioactives, making these matrices even more interesting as encapsulation systems (Jeong et al., 2007; Porter et al., 2007).

Quercetin (3, 3,4', 5,7-pentahydroxyflavone) is a flavonoid, and it is the major representative of the flavonol subclass. Dilating coronary arteries, decreasing blood lipid, antioxidation and anti-inflammation are some of the physiological effects that are attributed to this molecule (Inal \& Kahraman, 2000; Comalada et al., 2005; Kandaswami et al., 2005; Li et al., 2009; Ghosh et al., 2011; Landi-Librandi et al., 2012). However, because of its low hydrophilicity, quercetin has minimal absorption in the gastrointestinal tract, and its oral bioavailability is less than $17 \%$ in rats and less than $1 \%$ in humans (Li et al., 2009; Khaled et al., 2003; Gugler et al., 1975). The bioavailability and dispersibility of quercetin in aqueous media can be enhanced by encapsulation in lipid-based carriers, as previously cited. In this context, solid lipid particles are a good alternative for quercetin incorporation and has been used in some studies in the literature, though none of these studies focused on food applications.

One of the most important factors that affects the physico-chemical characteristics of solid lipid particles is the material of their lipid core. In the literature, several types of lipids have been used to produce such particles, from highly purified triacylglycerols and fatty acids to vegetable fats. The use of a vegetable fat, which is a mixture of triacylglycerols, can favorably affect their incorporation capacity and the stability of solid lipid particles because the crystalline structure of lipid particles is directly related to the chemical nature of the lipid that is used to produce it; such a structure is a crucial factor in the capacity of incorporation and preservation of a bioactive inside the particles (Müller et al., 2002; Mehnert \& Mäder, 2001; Weiss et al., 2008). A more disorganized crystalline structure corresponds to a higher particle capacity to incorporate bioactive molecules because the microstructural disorganization results in the presence of "voids" that can accommodate a large amount of the encapsulated substance. These voids can originate from

${ }^{1}$ Departamento de Engenharia de Alimentos, Faculdade de Zootecnia e Engenharia de Alimentos - FZEA, Universidade de São Paulo - USP, Pirassununga, SP, Brazil

*Corresponding author: samantha@usp.br 
mixing with different lipids or from using a mixture of lipids such as vegetable fats.

Different types of natural fats can be considered to produce solid lipid particles, e.g., palm kernel oil, coconut oil and cupuacu butter. Babacu oil is also an option to be considered. It is obtained from the small coconuts of a palm (Orbygnia speciosa) native from the Amazon forest (Brazil and Colombia); it is an oxidation-resistant lauric oil and presents more unsaturated fatty acids (10-26\% on a mass basis) than coconut oil (6-12\% on a mass basis). Despite its interesting composition, the potential uses of babacu oil in the food industry remain not fully explored (Reipert et al., 2011). Lauric-acid-rich lipids may have the advantage of increasing the bioavailability of encapsulated lipophilic molecules because MCTs (medium-chain triacylglycerides) can be hydrolyzed five times faster and more completely than long-chain triacylglycerides (LCTs) in the small intestine (Marten et al., 2006; Porter et al., 2007; Pouton \& Porter, 2008). In addition, MCTs are eliminated from the circulation twice as rapidly as LCTs, have a smaller effect on serum cholesterol levels and are not stored in body tissues when they are consumed in normal amounts (Marten et al., 2006; Porter et al., 2007).

Therefore, based on these factors, this study was conducted to investigate the stability of solid lipid microparticles that were produced with babacu oil and encapsulating quercetin. The physico-chemical stability of the lipid particles (produced with a mixture of babacu oil and tristearin and stabilized with whey protein isolate) during storage (30 days) under refrigeration was monitored. The quercetin concentration, average particle diameter, average size distribution, zeta potential and lipid oxidation were obtained. In addition, the stability of the solid lipid microparticles was assessed after their exposition to different stress conditions: thermal treatments, different ionic strengths, concentrations of sucrose and $\mathrm{pH}$, which can be easily found in food-processing operations.

\section{Materials and methods}

\subsection{Materials}

Babacu oil (Orbignya speciosa) (BO) was obtained from Casa do Saboeiro (Santa Bárbara D'Oeste, SP, Brazil). Tristearin (TS) and quercetin (CAS 117-39-5) were obtained from Sigma (St Louis, MO, USA), and whey protein isolate (WPI) was obtained from Alibra (product CL3987, Campinas, SP, Brazil). Xanthan gum (GRINDSTED Xanthan 80, Danisco, Cotia, SP, Brazil) was used as the thickening agent. Other reagents and organic solvents were of analytical grade. Deionized water from a Millipore system (Milli-Q, Billerica, MA, USA) was used throughout the experiments.

\subsection{Production of lipid microparticles (LM)}

A stock dispersion of WPI ( $5 \% \mathrm{~m} / \mathrm{v})$ was initially prepared, and its $\mathrm{pH}$ was adjusted to 7.0 using $\mathrm{NaOH} 2.0 \mathrm{M}$. Lipid microparticles were produced by melting the lipid phase (TS and $\mathrm{BO}, 1.5$ and $3.5 \% \mathrm{w} / \mathrm{w}$, respectively) at $70{ }^{\circ} \mathrm{C}$ and subsequently adding the quercetin $(0.3 \mathrm{mg} / \mathrm{mL}$ of dispersion). The hot WPI dispersion (diluted to $1.25 \% \mathrm{~m} / \mathrm{v}$ ) solution at $70^{\circ} \mathrm{C}$ was mixed with the melted lipid and submitted to an ultra-agitation of 12,000 rpm for 5 min using an ultra-turrax (IKA T25, IKA,
Staufen, Germany). The DSC analyses show that the WPI was completely denatured at these conditions (data not shown). Then, the dispersions were magnetically stirred, xanthan gum was added $(0.05 \% \mathrm{w} / \mathrm{w})$, and the lipid microparticle dispersions were subsequently cooled to $20^{\circ} \mathrm{C}$ in an ice bath. The formulations, which were produced in triplicate, were stored at $7-10{ }^{\circ} \mathrm{C}$. Sodium benzoate $(0.02 \% \mathrm{~m} / \mathrm{v})$ was added to the samples to avoid microbiological contamination. The samples were stored in glass vials, protected from light.

\subsection{Determination of particle size distribution and zeta potential}

The average hydrodynamic diameter and size distribution of the lipid microparticles were obtained using photon correlation spectroscopy with a ZetaPlus (Brookhaven Instruments Company, Holtsville, NY, USA) at $25{ }^{\circ} \mathrm{C}$. The samples were diluted with ultra-purified water to weaken their opalescence before measuring the particle mean diameter. The zeta potential was analyzed after diluting the sample in ultra-pure water, and it was calculated from the electrophoretic mobility using the Helmholtz-Smoluchowski equation. The data analyses were performed using the software included with the equipment.

\subsection{Quantification of quercetin encapsulated in lipid microparticles}

The quantification protocol of encapsulated quercetin was adapted from Pool et al. (2013). The lipid microparticles were added to DMSO (dimethylsulphoxide) (volume ratio 1:25), and the resulting solution was filtered in membranes of $0.45 \mu \mathrm{m}$ thickness (Millex LCR, Millipore, Billerica, MA, USA) to eliminate any aggregates. The absorbance of the samples were read at $373 \mathrm{~nm}$ (Libra S22, Biochrom, Oxford, England). The quercetin concentrations were determined from the standard curve of the flavonoid, which was solubilized in DMSO with a correlation coefficient of 0.9996 , in the range of $0-10 \mu \mathrm{g}$ quercetin $/ \mathrm{mL}$.

\subsection{Evaluation of lipid oxidation using TBARS}

A solution of TCA (trichloroacetic acid)-TBA-HCl was prepared by mixing $75 \mathrm{~g}$ of TCA, $1.68 \mathrm{~g}$ of TBA, $8.8 \mathrm{~mL}$ of $12 \mathrm{M} \mathrm{HCl}$, and $414 \mathrm{~g}$ of $\mathrm{H} 2 \mathrm{O}$. One hundred milliliters of TCA-TBA-HCl solution was mixed with $3 \mathrm{~mL}$ of $2 \%(\mathrm{w} / \mathrm{w})$ butylated hydroxytoluene in ethanol, and $2 \mathrm{~mL}$ of this solution was mixed with $2 \mathrm{~mL}$ of the LM sample. After mixing, the mixture was heated in a boiling water bath for $15 \mathrm{~min}$, cooled to room temperature and centrifuged at $1000 \mathrm{~g}$ for $10 \mathrm{~min}$ (5810R, Eppendorf). Then, the absorbance was measured at $532 \mathrm{~nm}$ using a spectrophotometer (Libra S22, Biochrom, Oxford, England). The TBARS concentrations were determined from the standard curve prepared using 1,1,3,3-tetraethoxypropan (TEP concentration of 0-0.500 mg/L, correlation coefficient of 0.9968 ) (Lee et al., 2011).

\subsection{Morphological analyses using optical microscopy}

The lipid microparticles were observed using an optical microscopy (BEL PHOTONIX, 1.3 MP optical camera), and the images were captured using the software BEL VIEW with a magnification of 100x. The samples were diluted $2 \mathrm{x}$ before visualization. 


\subsection{Physicochemical stability of lipid microparticles under different stress conditions}

The physicochemical stability of the lipid microparticles was assessed by measuring the average particle size and visualizing the phase separation. The experimental protocols were based on Thanasukarn et al. (2006) and Silva et al. (2014).

Effect of $\mathrm{pH}$ : The $\mathrm{pH}$ of the lipid microparticles, which initially ranged from 5.0 to 5.7 , was adjusted to either 3.0 or 8.0 by adding $0.01 \mathrm{~mol} / \mathrm{L} \mathrm{HCl}$ or $0.01 \mathrm{~mol} / \mathrm{L} \mathrm{NaOH}$, respectively. A specific volume of each type of dispersion was subsequently poured into a test tube, capped and stored under refrigerated conditions.

Effect of thermal treatments: The samples were subjected to temperatures in the range of $30-80{ }^{\circ} \mathrm{C}$ by placing the test tubes with the lipid microparticles in a water bath at these temperatures. The particle size distributions were determined after 2, 5 and 10 minutes of treatment.

Effect of the salt concentration: Different amounts of sodium chloride $(\mathrm{NaCl})$ were added to the particle dispersions, which resulted in salt concentrations of $0.25-1.0 \mathrm{~mol} / \mathrm{L}$. The lipid microparticles were vigorously shaken and stored under refrigerated conditions. The mixing was performed at room temperature using two different methods: magnetically and mechanically (300 rpm, Cowles disk impeller).

Effect of the sugar concentration: Different amounts of sucrose were added to the microparticle dispersions, which resulted in sucrose concentrations of $0.5-7.0 \% \mathrm{w} / \mathrm{v}$. The nanoemulsions were vigorously shaken and stored under refrigerated conditions before the phase separation, and the particle size distributions were determined. The mixing was performed at room temperature using two different methods: magnetically and mechanically (at $300 \mathrm{rpm}$, using a Cowles disk impeller).

\subsection{Thermal behavior by differential scanning calorimetry (DSC)}

The thermal analyses of lipid microparticles using DSC were performed using a ramp of $10^{\circ} \mathrm{C} / \mathrm{min}$ in the range of $0-100{ }^{\circ} \mathrm{C}$ with a TA5000 (TA Instruments, New Castle, DE, EUA). An empty aluminum pan was used as the reference.

\subsection{Statistical analyses}

All experiments were conducted in triplicates, and the data are presented as average \pm standard deviation. Tukey tests were performed to compare the mean values. The significance level for all tests was $5 \%$, which was calculated using SAS software version 9.2.

\section{Results and discussion}

\subsection{Physico-chemical characterization and stability along the storage period}

Figure 1 shows the particle size distribution of the lipid microparticles that encapsulated quercetin, which were produced with a mixture of tristearin and babacu oil, during the storage period. Table 1 shows the zeta potential, quercetin concentration and lipid oxidation till the 30th day of storage.

The size distribution curves show that the system remained notably stable over 30 days of storage under refrigeration, and the distribution was monomodal with an average size of approximately $0.90 \mu \mathrm{m}$.

The zeta potential values were lower than $-30 \mathrm{mV}$, which indicates the stability of the colloidal system. There also were not significant losses of the encapsulated quercetin after 30 days of storage. Regarding the TBARs products of lipid oxidation, the data there was a statistical difference among the values for fresh and 30-day stored samples, but indicate they were present in a notably low concentration, which also indicates the chemical stability of the fatty acids present in the oil core of lipid microparticles.

The number of studies about the encapsulation of quercetin in lipid microparticles (nano or micro) has been increasing in the last five years (Li et al., 2009; Dhawan et al., 2011; Weiss-Angeli et al., 2012; Pool et al., 2013; Aditya et al., 2014; Han et al., 2014), but most studies have not evaluated the stability of encapsulated

Table 1. Characteristics of the quercetin-loaded lipid microparticles that were produced with babacu oil and tristearin and stabilized with denatured whey protein isolate at the beginning and the end of the storage period.

\begin{tabular}{ccc}
\hline Parameter & Fresh samples & $\begin{array}{c}\text { After 30 days of } \\
\text { storage }\end{array}$ \\
\hline Average hydrodynamic & $1.09 \pm 0.13^{\mathrm{a}}$ & $0.862 \pm 0.036^{\mathrm{b}}$ \\
diameter $(\mu \mathrm{m})$ & & \\
Zeta potential $(\mathrm{mV})$ & $-42.4 \pm 3.02^{\mathrm{a}}$ & $-41.4 \pm 3.64^{\mathrm{a}}$ \\
Quercetin $(\mathrm{mg} / \mathrm{L})$ & $173.5 \pm 6.80^{\mathrm{a}}$ & $180.1 \pm 13.96^{\mathrm{a}}$ \\
TBARs $(\mathrm{mmol} / \mathrm{kg}$ oil $)$ & $1.94 \pm 0.20^{\mathrm{a}}$ & $1.34 \pm 0.20^{\mathrm{b}}$ \\
\hline
\end{tabular}

Identical letters in a column indicate no significant difference according to Tukey's test $(\mathrm{p}<0.05)$

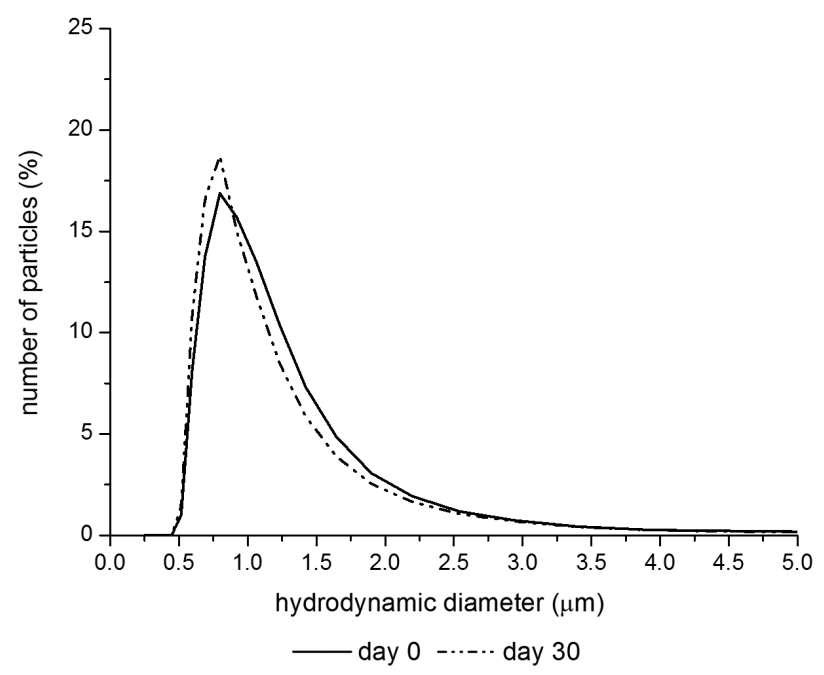

Figure 1. Particle size distribution curves of the dispersions of lipid microparticles that were produced with tristearin and babacu oil during the storage period. 
quercetin over the storage period. Scalia \& Mezzena (2009) evaluated the stability of encapsulated quercetin in lipid microparticles that were composed of tristearin as the solid core and phosphatidylcholine as the surfactant, which were produced using ultra-agitation (mean diameters of 15-45 $\mu \mathrm{m}$ ), and they found that $85 \%$ of the flavonoid remained in the particles after 90 days of storage in the dark.

Figure 2 shows the thermogram of the lipid microparticles, which was obtained using differential scanning calorimetry (DSC). Two endothermic peaks appeared and reflect the heterogeneous lipid composition of the system. The low-temperature peak (at approximately $32{ }^{\circ} \mathrm{C}$ ) can be associated with the structure formed by the medium chain triglycerides in the babacu oil, which was composed of $48 \%$ of lauric acid (in terms of fatty acids). The higher-temperature peak (at $50.75^{\circ} \mathrm{C}$ ) was related to the structures that were formed by the long-chain triglycerides (Silva et al., 2014).

\subsection{Stability of the lipid microparticles under different stress conditions}

Regarding the stability under the temperature stresses that were applied to the dispersions, for the temperatures of $30-80^{\circ} \mathrm{C}$, the lipid microparticles appeared notably stable even at higher temperatures for longer periods, as can be seen in Figure 3. The lipid microparticles were resistant to significant changes in size distribution up to $40{ }^{\circ} \mathrm{C}$ for all tested periods of time. From $50^{\circ} \mathrm{C}$ to $70^{\circ} \mathrm{C}$, the particles exhibited less resistance to heat, which can be explained by a higher rate of partial coalescence. This phenomenon occurs when two or more partially crystalline particles join together to form a non-spherical structure, as in the case of the lipid microparticles produced here and shown in Figure 2 (Dickinson \& McClements, 1996). The fat crystals stick out through the oil-water interface, the protruding crystals of one particle penetrate into another particle, and the particles remain aggregated because the crystals are wetted better by oil than by water, and because the surface area of fat that is exposed to the aqueous phase decreases (Boode et al., 1993; Dickinson \& McClements, 1996).

Regarding the stability of the lipid microparticles under different ionic strengths shows two distinct behaviors can be distinguished: in the experiments where magnetic stirring was used, all samples destabilized immediately after the addition of salt, as shown in Figure 4. However, in the experiments with salt added under mechanical stirring, no sample destabilized; the resultant size distribution curves are shown in Figure 5. For these identical tests, the quercetin concentrations were determined, and the results are shown in Table 2.

There were statistical significant differences among the values of quercetin concentration encapsulated in the samples subjected to $0.75 \mathrm{M} \mathrm{NaCl}$, however, as a whole, the average percentage of remaining quercetin after 10 days of ionic strength stress was $94.5 \%$, which can be considered a very high value. These results indicate the WPI-stabilized lipid microparticles encapsulating quercetin are quite resistant to relative high salt concentrations.

The effect of adding sucrose to the lipid microparticles also strongly depended on the type of stirring for the system. For the mechanically stirred systems, the samples destabilized after 7 days of incubation, and the particle size distributions

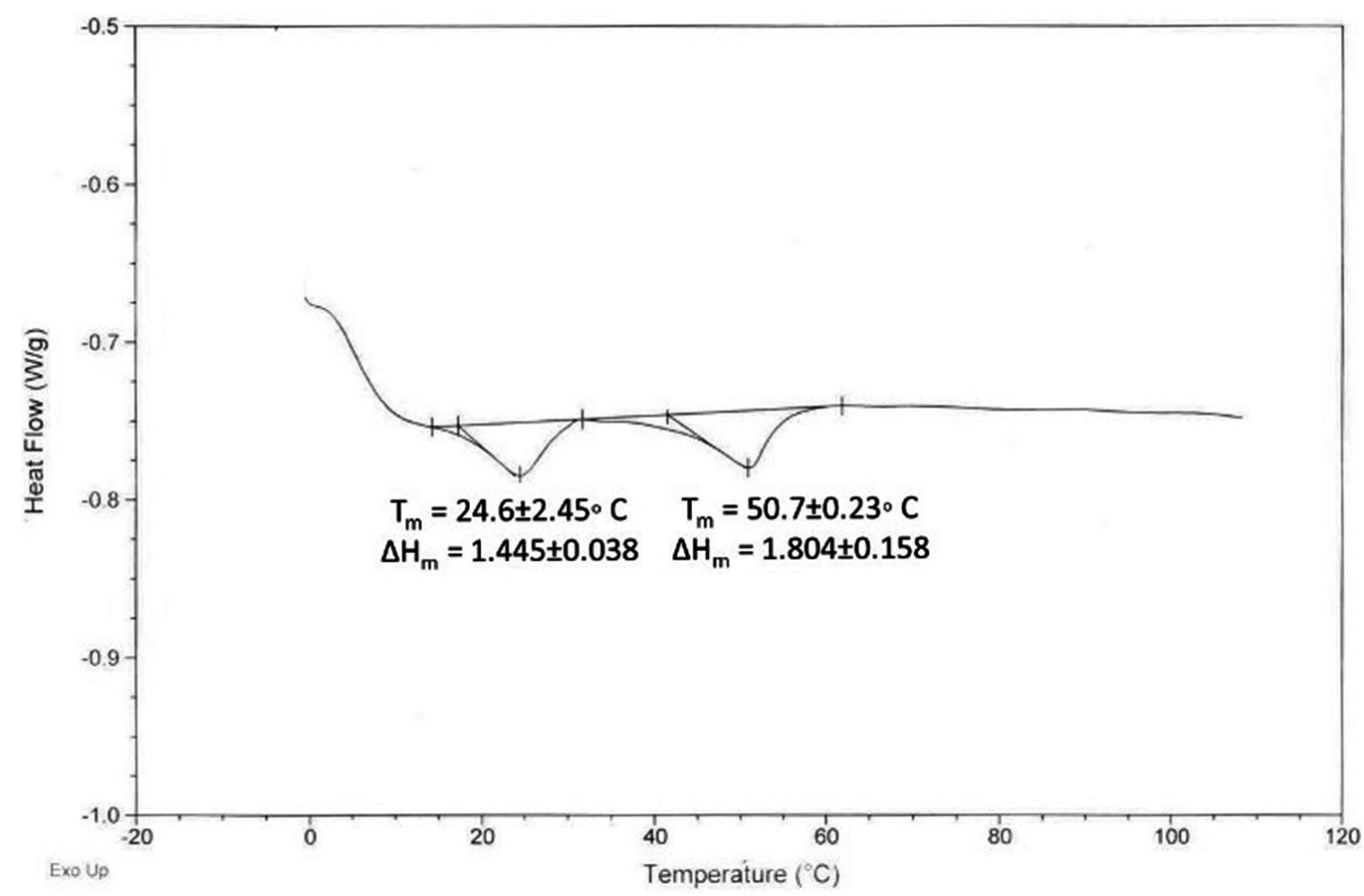

Figure 2. Calorimetric behavior of lipid microparticles that were produced with babacu oil and tristearin, which was obtained using differential scanning calorimetry (DSC). 

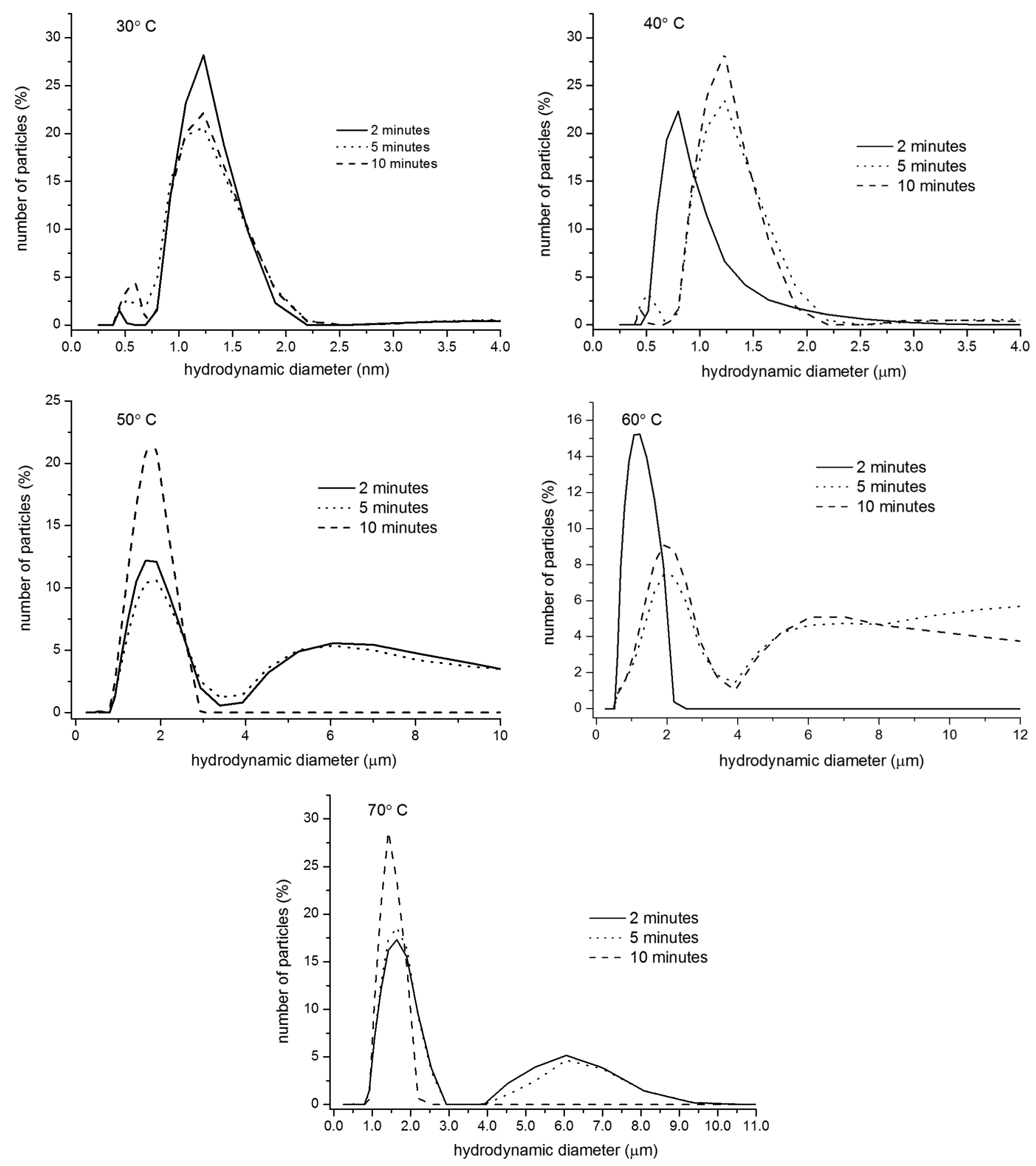

Figure 3. Particle size distributions of the lipid microparticles, which were produced using babacu oil and tristearin and stabilized with WPI, after the thermal stresses at different temperatures.

are shown in Figure 6 . The samples with 5 and $7 \%$ of sucrose were destabilized (phase separation) in less than 24 hours of incubation. Regarding the influence of sucrose on the stability of WPI-stabilized lipid microparticles, Thanasukarn et al. (2006) states the presence of sucrose may increase the conformational stability of the adsorbed globular proteins, as the proteins present in the whey protein isolate. Such an effect may have occurred up to the concentration of $3 \%$ of sucrose. 
The magnetically stirred samples destabilized for all concentrations of added sucrose, as occurred with the samples that were submitted to various ionic strengths. Figure 7 shows the visual aspect of the lipid-microparticle dispersions that were

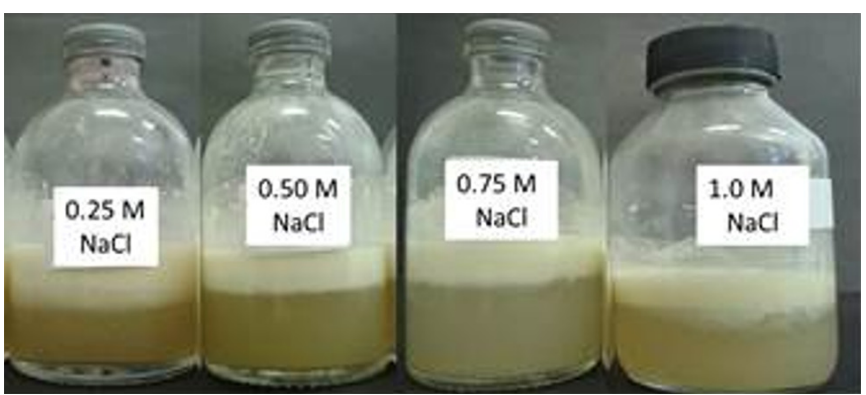

Figure 4. Visual aspect of the lipid-microparticle dispersions, which were produced using tristearin and babacu oil, encapsulated quercetin, and submitted to different ionic strengths under magnetic stirring, after 24 hours of storage under refrigeration. submitted to different sucrose concentrations under magnetic stirring. It was observed that an extensive flocculation process occurred. Therefore, it can be concluded that the destabilization of the samples can be decreased or even avoided if the suitable stirring condition is applied to the system. Regarding encapsulated quercetin, the presence of sucrose did not seem to affect in the samples which remained stable in terms of average size, up to

Table 2. Quercetin concentration values of babacu lipid microparticles submitted to various ionic strengths (under mechanical strirring), on days 1 and 10 of storage.

\begin{tabular}{clc}
\hline \multirow{2}{*}{$\operatorname{NaCl}(\mathrm{M})$} & \multicolumn{2}{c}{ Quercetin $(\mu \mathrm{g} / \mathrm{mL})$} \\
\cline { 2 - 3 } & Fresh samples & Day 10 \\
\hline 0.25 & $128.2 \pm 12.84^{\mathrm{a}, \mathrm{A}}$ & $122.6 \pm 10.0^{\mathrm{a}, \mathrm{A}}$ \\
0.50 & $133.9 \pm 10.10^{\mathrm{a}, \mathrm{A}}$ & $130.4 \pm 13.1^{\mathrm{a}, \mathrm{A}}$ \\
0.75 & $128.6 \pm 4.24^{\mathrm{a}, \mathrm{A}}$ & $118.9 \pm 1.20^{\mathrm{b}, \mathrm{A}}$ \\
1.0 & $117.4 \pm 11.0^{\mathrm{a}, \mathrm{A}}$ & $110.3 \pm 10.2^{\mathrm{a}, \mathrm{A}}$ \\
\hline
\end{tabular}

Average values with identical lowercase letters in the same line and uppercase letters in the same column were not significantly different $(p>0.05)$ according to Tukey's test.
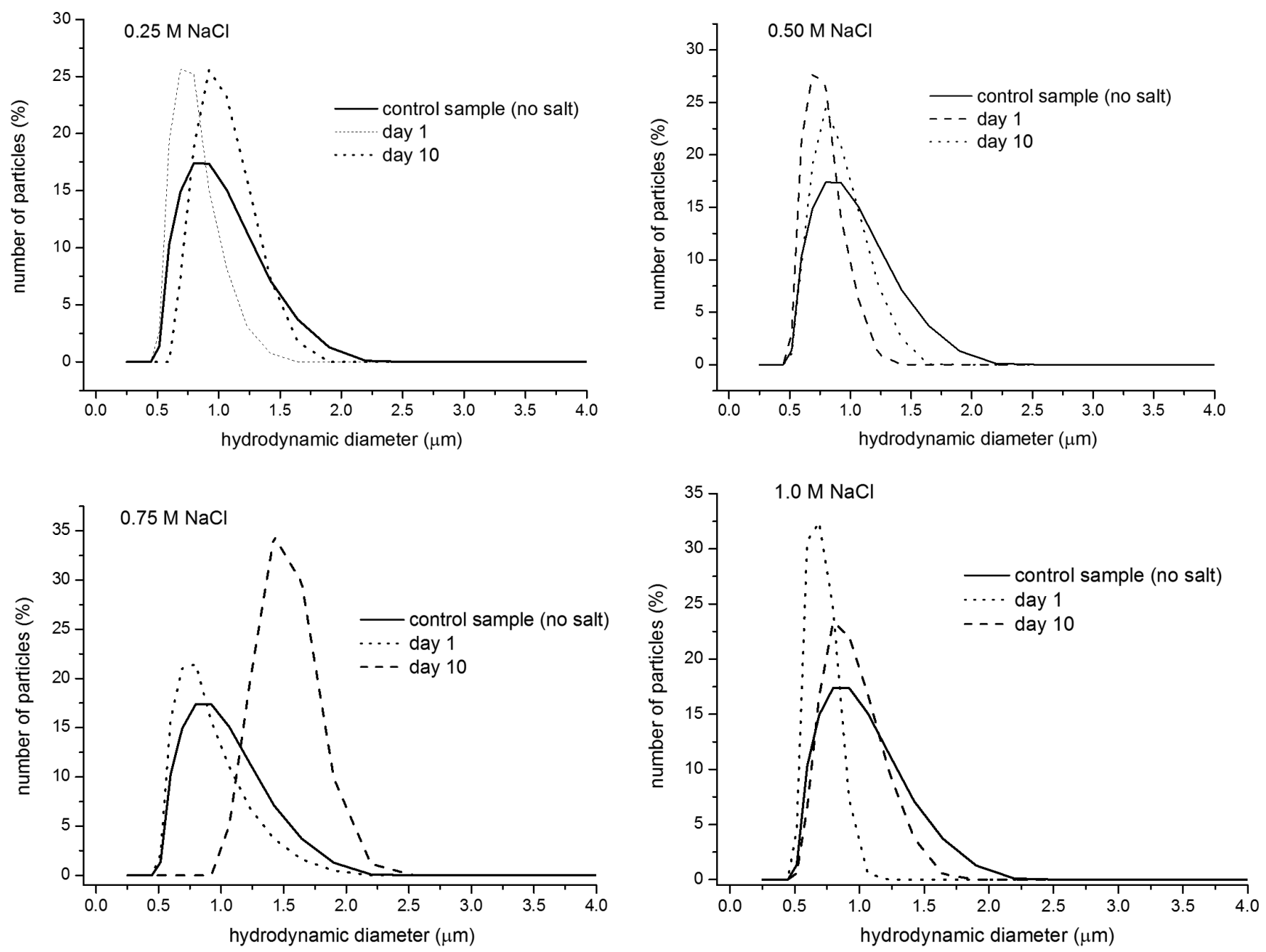

Figure 5. Particle size distributions of the lipid microparticles, which were produced using babacu oil and tristearin and stabilized with WPI, after they were submitted to different ionic strengths (salt added under mechanical stirring). 

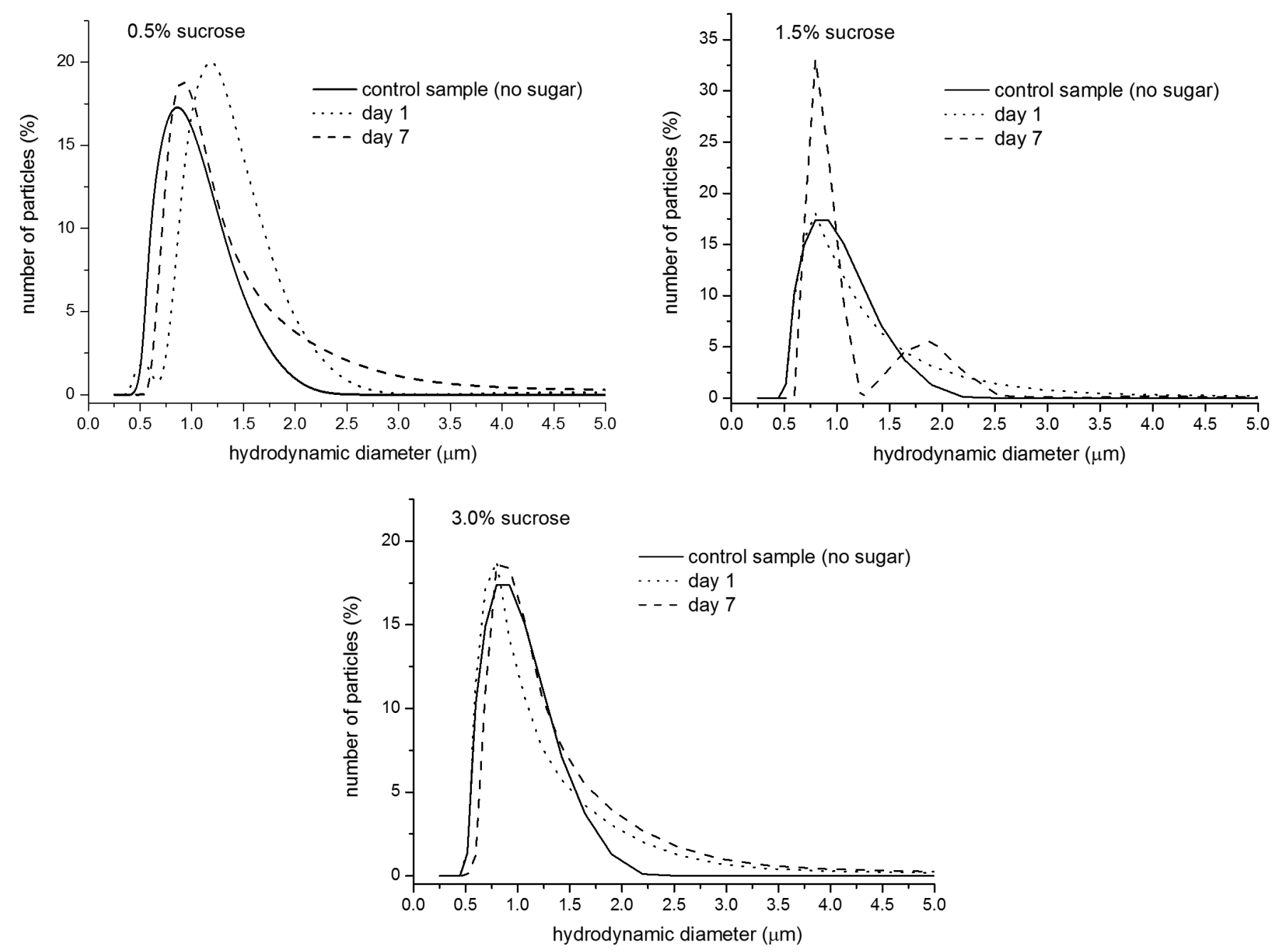

Figure 6. Particle size distributions of the lipid microparticles, which were produced using babacu oil and tristearin and stabilized with WPI, after they were submitted to different sucrose concentrations (added under mechanical stirring).

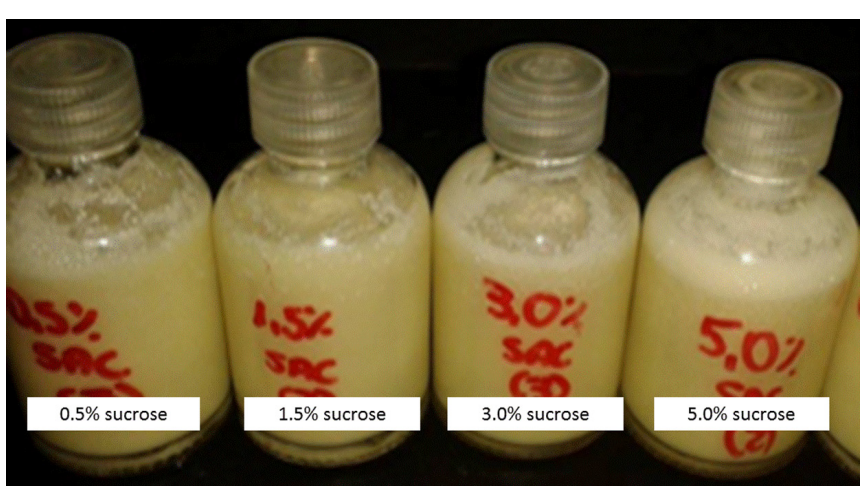

Figure 7. Visual aspect of the lipid-microparticle dispersions, which were produced using tristearin and babacu oil, encapsulated quercetin, and submitted to different sucrose concentrations under magnetic stirring, after 24 hours of storage under refrigeration.

the $10^{\text {th }}$ day of storage, as can be seen in Table 3 . The suitable stirring condition can avoid heterogeneous concentrations (local very high concentration spots) of solutes in the dispersions, which is especially important in protein-stabilized dispersions.
Table 3. Quercetin concentration values of babacu lipid microparticles, which were submitted to various sucrose concentrations (added under mechanical stirring), on days 1 and 7 of storage.

\begin{tabular}{ccc}
\hline $\begin{array}{c}\text { Sucrose } \\
(\mathrm{w} / \mathrm{v})\end{array}$ & \multicolumn{2}{c}{ Quercetin $(\mu \mathrm{g} / \mathrm{mL})$} \\
\cline { 2 - 3 } $0.5 \%$ & $167.0 \pm 9.50^{\mathrm{a}, \mathrm{A}}$ & Day 10 \\
\hline $1.0 \%$ & $171.2 \pm 4.38^{\mathrm{a}, \mathrm{A}}$ & $160.8 \pm 2.63^{\mathrm{a}, \mathrm{A}}$ \\
$3.0 \%$ & $165.2 \pm 3.60^{\mathrm{a}}$ & (phase separation) \\
$5.0 \%$ & $190.1 \pm 17.2^{\mathrm{A}}$ & (phase separation) \\
$7.0 \%$ & $113.5 \pm 3.64^{\mathrm{B}}$ & (phase separation) \\
\hline
\end{tabular}

Average values with identical lowercase letters in the same line and uppercase letters in the same column were not significantly different $(\mathrm{p}>0.05)$ according to Tukey's test.

\section{Conclusions}

The babacu oil lipid microparticles that were produced with denatured WPI as the surfactant were stable over 30 days of storage, and they could protect quercetin against the degradation processes. They presented a highly heterogeneous lipid core, as expected and proven by DSC, which certainly 
helped preserving the encapsulated flavonoid. Additionally, the babacu oil microparticles demonstrated a high potential to be incorporated in food formulations because they exhibited a high degree of stability under the typical ionic strength, sucrose concentrations and thermal stresses in food processing. Particularly, the type and condition of stirring (mechanical or magnetic) strongly affect the stability of the lipid microparticles in the presence of salt or sucrose. These results indicate that the babacu oil microparticles can be incorporated into food matrices if they are correctly engineered. The results of this study can be useful for designing effective delivery systems to encapsulate and stabilize quercetin for food product applications.

\section{Acknowledgements}

The authors thank the University of São Paulo (USP, Pró-Reitoria de Graduação) for the fellowship (Camila P. S. Cazado).

\section{References}

Aditya, N. P., Macedo, A. S., Doktorovova, S., Souto, E. B., Kim, S., Chang, P-S., \& Ko, S. (2014). Development and evaluation of lipid nanocarriers for quercetin delivery: a comparative study of solid lipid nanoparticles (SLN), nanostructured lipid carriers (NLC), and lipid nanoemulsions (LNE). LWT- Food Science and Technology, 59, 115-121. http://dx.doi.org/10.1016/j.lwt.2014.04.058

Boode, K., Walstra, P. A., \& Groot-Mostert, E. A. (1993). Partial coalescence in oil-in-water emulsions 2. Influence of the properties of the fat. Colloids and Surfaces. A, Physicochemical and Engineering Aspects, 81, 139-151. http://dx.doi.org/10.1016/0927-7757(93)80240-F.

Comalada, M., Camuesco, D., Sierra, S., Ballester, I., Xaus, J., Galvez, J., \& Zarzuelo, A. (2005). In vivo quercitrin anti-inflammatory effect involves release of quercetin, which inhibits inflammation through down-regulation of the NF-kappaB pathway. European Journal of Immunology, 35(2), 584-592. http://dx.doi.org/10.1002/ eji.200425778. PMid:15668926.

Dhawan, S., Kapil, R., \& Singh, B. (2011). Formulation development and systematic optimization of solid lipid nanoparticles of quercetin for improved brain delivery. Journal of Pharmacy and Pharmacology, 63, 342-351. http://dx.doi.org/10.1111/j.2042-7158.2010.01225.x

Dickinson, E., \& McClements, D. J. (1996). Fat crystallization in oilin-water emulsions. In E. Dickinson \& D. J. McClements (Eds.), Advances in food colloids (pp. 211). Glasgow: Blackie Academic \& Professional.

Ghosh, A., Mandal, A. K., Sarkar, S., \& Das, N. (2011). Hepatoprotective and neuroprotective activity of liposomal quercetin in combating chronic arsenic induced oxidative damage in liver and brain of rats. Drug Delivery, 18(6), 451-459. http://dx.doi.org/10.3109/10717544 .2011.577110. PMid:21554158.

Gugler, R., Leschik, M., \& Dengler, H. J. (1975). Disposition of quercetin in man after single oral and intravenous doses. European Journal of Clinical Pharmacology, 9(2-3), 229-234. http://dx.doi.org/10.1007/ BF00614022. PMid:1233267.

Han, S. B., Kwon, S. S., Jeong, Y. M., Yu, E. R., \& Park, S. N. (2014). Physical characterization andin vitro skin permeation of solid lipid nanoparticles for transdermal delivery of quercetin. International Journal of Cosmetic Science, 36, 588-597. http://dx.doi.org/10.1111/ ics. 12160

Inal, M. E., \& Kahraman, A. (2000). The protective effect of flavonol quercetin against ultraviolet $\mathrm{A}$ induced oxidative stress in rats.
Toxicology, 154(1-3), 21-29. http://dx.doi.org/10.1016/S0300483X(00)00268-7. PMid:11118667.

Jeong, S. H., Park, J. H., \& Park, K. (2007). Formulation issues around lipid-based oral and parenteral drug delivery systems. In K. M. Wasan (Ed.), Role of lipid expients in modifying oral and parenteral drug delivery. Hoboken: Wiley- Interscience.

Kandaswami, C., Lee, L. T., Lee, P. P., Hwang, J. J., Ke, F. C., Huang, Y. T., \& Lee, M. T. (2005). The antitumor activities of flavonoids. In Vivo (Athens, Greece), 19(5), 895-909. PMid:16097445.

Khaled, K. A., El-Sayed, Y. M., \& Al-Hadiya, B. M. (2003). Disposition of the flavonoid quercetin in rats after single intravenous and oral doses. Drug Development and Industrial Pharmacy, 29(4), 397-403. http://dx.doi.org/10.1081/DDC-120018375. PMid:12737533.

Landi-Librandi, A. P., Azzolini, A. E. C. S., Oliveira, A. C., \& LucianoValim, Y. M. (2012). Inhibitory activity of liposomal flavonoids during oxidative metabolism of human neutrophils upon stimulation with immune complexes and phorbol ester. Drug Delivery, 19(4), 177-187. http://dx.doi.org/10.3109/10717544.2012.679710. PMid:22533556.

Lee, S. J., Choi, S. J., Li, Y., Decker, E. A., \& McClements, D. J. (2011). Protein-stablized nanoemulsions and emulsions: comparison of physicochemical stability, lipid oxidation and lipase digestibility. Journal of Agricultural and Food Chemistry, 59(1), 415-427. http:// dx.doi.org/10.1021/jf103511v. PMid:21133433.

Li, H., Zhao, X., Ma, Y., Zhai, G., Li, L., \& Lou, H. (2009). Enhancement of gastrointestinal absorption of quercetin by solid lipid nanoparticles. Journal of Controlled Release, 133(3), 238-244. http://dx.doi. org/10.1016/j.jconrel.2008.10.002. PMid:18951932.

Marten, B., Pfeuffer, M., \& Schrezenmeier, J. (2006). Medium-chain triglycerides. International Dairy Journal, 16(11), 1374-1382. http:// dx.doi.org/10.1016/j.idairyj.2006.06.015

McClements, D. J. (2010). Design of nano-laminated coatings to control bioavailability of lipophilic food components. Journal of Food Science, 75(1), 30-42. http://dx.doi.org/10.1111/j.1750-3841.2009.01452.x

McClements, D. J., \& Li, Y. (2010). Structured emulsion-based delivery systems: controlling the digestion and release of lipophilic food components. Advances in Colloid and Interface Science, 159(2), 213228. http://dx.doi.org/10.1016/j.cis.2010.06.010. PMid:20638649.

Mehnert, W., \&, Mäder, K. (2001). Solid lipid nanoparticles: production, characterization and applications. Advanced Drug Delivery Reviews, 47, 165-169. http://dx.doi.org/10.1016/S0169-409X(01)00105-3

Müller, R. H., Mader, K., \& Gohla, S. (2000). Solid lipid nanoparticles (SLN) for controlled drug delivery: a review of the state of the art. European Journal of Pharmaceutics and Biopharmaceutics, 50, 161177. http://dx.doi.org/10.1016/S0939-6411(00)00087-4

Müller, R. H., Radtke, M., \& Wissing, S. A. (2002). Nanostructured lipid matrices for improved microencapsulation of drugs. International Journal of Pharmaceutics, 242, 121-128. http://dx.doi.org/10.1016/ S0378-5173(02)00180-1

Pool, H., Mendoza, S., Xiao, H., \& McClements, D. J. (2013). Encapsulation and release of hydrophobic bioactivecomponents in nanoemulsion-based delivery systems:impact of physical form on quercetin bioaccessibility. Food \& Function, 4(1), 162-174. http:// dx.doi.org/10.1039/C2FO30042G. PMid:23172078.

Porter, C. J. H., Trevaskis, N. L., \& Charman, W. N. (2007). Lipids and lipid-based formulations: optimizing the oral delivery of lipophilic drugs. Nature Reviews. Drug Discovery, 6(3), 231-248. http://dx.doi. org/10.1038/nrd2197. PMid:17330072.

Pouton, C. W., \& Porter, C. J. H. (2008). Formulation of lipid-based delivery systems for oral administration: materials, methods and 
strategies. Advanced Drug Delivery Reviews, 60, 625-637. http:// dx.doi.org/10.1016/j.addr.2007.10.010

Reipert, E. D., Rodrigues, C. E. C., \& Meirelles, A. J. (2011). Phase equilibria study of systems composed of refined babassu oil, lauric acid, ethanol, and water at 303.2 K. The Journal of Chemical Thermodynamics, 43(12), 1784-1790. http://dx.doi.org/10.1016/j. jct.2011.05.039.

Scalia, S., \& Mezzena, M. (2009). Incorporation of quercetin in lipid microparticles: Effect on photo- and chemical-stability. Journal of Pharmaceutical and Biomedical Analysis, 49, 90-94. http://dx.doi. org/10.1016/j.jpba.2008.10.011

Silva, J. C., Borrin, T. R., Ruy, P., Brito, T. C., Pinheiro, A. C., Vicente, A. A., \& Pinho, S. C. (2014). Characterization, physicochemical stability, and evaluation of in vitro digestibility of solid lipid microparticles produced with palm kernel oil and tristearin. Food
Science and Technology (Campinas.), 34(3), 532-538. http://dx.doi. org/10.1590/1678-457x.6359.

Thanasukarn, P., Pongsawatmanit, R., \& McClements, D. J. (2006). Impact of fat and water crystallization on the stability of hydrogenated palm oil-in-water emulsions stabilized by a nonionic surfactant. Journal of Agricultural and Food Chemistry, 54(10), 3591-3597. http://dx.doi. org/10.1021/jf0524630. PMid:19127730.

Weiss, J., Decker, E. A., McClements, D. J., Kristbergsson, K., Helgason, T., \& Awad, T. (2008). Solid lipid nanoparticles as delivery systems for bioactive food components. Food Biophysics, 3(2), 146-154. http://dx.doi.org/10.1007/s11483-008-9065-8

Weiss-Angeli, V., Poletto, F. S., de Marco, S. L., Salvador, M., Silveira, N. P., Guterres, S. S., \& Pohlmann, A. R. (2012). Sustained antioxidant activity of quercetin-loaded lipid-core nanocapsules. Journal of Nanoscience and Nanotechnology, 12, 2874-2850. http://dx.doi. org/10.1166/jnn.2012.5770 